\title{
Generic - equivalent drugs use in internal and general medicine patients: distrust, confusion, lack of certainties or of knowledge? Part 3. Clinical issues
}

\author{
Roberto Nardi, ${ }^{1}$ Marco Masina, ${ }^{2}$ Giorgio Cioni, ${ }^{3}$ Paolo Leandri, ${ }^{1}$ Paola Zuccheri ${ }^{4}$ \\ ${ }^{1}$ UOC Medicina Interna, AUSL Bologna, Ospedale Maggiore, Bologna; ${ }^{2}$ UOC Geriatria, AUSL Bologna, Ospedale di \\ Bentivoglio (BO); ${ }^{3}$ UOC Medicina Interna, AUSL di Modena, Pavullo nel Frignano (MO); ${ }^{4}$ Farmacia Clinica H e Continuità \\ H/T, AUSL Bologna, Ospedale Maggiore, Bologna, Italy
}

\begin{abstract}
There are several clinical areas or types of drugs that make prescribing branded drugs preferable, because of potential therapeutic inequivalence or confusion. Bioequivalence criteria may be fine for most drugs, but some conditions may require drug levels with modified variations, like in the case of narrow therapeutic index and critical dose drugs, highly variable drugs and modified-release formulations. Moreover, substitution with generics can be problematic in some patient subpopulations, such as elderly frail people, immunocompromised and transplant patients and patients with epilepsy. We include a list of branded drugs that are considered safer, more effective or with a lower risk of error. The therapeutic substitution is markedly different from therapeutic interchange. The replacement of a brand product with an equivalent has to occur under the control of the physician. At some point in their interaction with individual patients, physicians should let them know that generics are available as substitutes for the more expensive brand-name medications and are equivalent in terms of efficacy and safety. Finally, we hope that a tool like the American Orange book will be also implemented in Italy: it would serve as an accurate reference, that can be useful both to physicians for prescription appropriateness and to patients for their own informed consent.
\end{abstract}

\section{The practical use of equivalent drugs}

In the clinical practice, several aspects associated with the use of equivalent drugs need to be considered (Table 1).

\section{Determination of bioequivalence by means of studies in healthy volunteers as a single dose}

Bioequivalence studies are performed on healthy

Correspondence: Roberto Nardi, via C. Pavese 16/2, 40141 , Bologna, Italy.

Tel.: +39.335.8291342.

E-mail: nardidoc48@gmail.com

Key words: generic/equivalent drugs, clinical issues, narrow therapeutic index and critical dose drugs, highly variable drugs, special subpopulations, therapeutic substitution and therapeutic interchange.

Received for publication: 11 June 2013.

Revision received: 23 August 2013.

Accepted for publication: 23 August 2013.

This work is licensed under a Creative Commons Attribution NonCommercial 3.0 License (CC BY-NC 3.0).

C Copyright R. Nardi et al., 2014

Licensee PAGEPress, Italy

Italian Journal of Medicine 2014; 8:99-109

doi:10.4081/itjm.2014.400 volunteers. It is conventionally accepted that a similar bioavailability found in these people is a solid proof of a similar bioavailability in sick people! This model applied in vivo on healthy volunteers is considered adequate in most instances to detect formulation differences and to allow extrapolation of results to populations for which the reference medicinal product is approved (elderly, children, patients with renal or liver impairment, etc.). Another critical aspect of bioequivalence research is that it is recognized on the basis of studies carried out on a single dose, despite in clinical practice these drugs are administered in repeated doses to chronic patients. ${ }^{1}$ In this respect, one might wonder whether single-dose studies on a limited number of healthy volunteers can adequately mirror the use of drugs in real life and whether the same results apply the most common groups of patients?. ${ }^{2}$ According to some, in certain cases bioavailability tests need to be carried out on real patients. The question is not so much whether patients are different from volunteers, but rather whether, and when, these differences could cause two products that seem bioequivalent in normals become bioinequivalent in a clinical setting. A literature review aimed to study these factors in real patients has shown that only very few relevant publications are available on this topic. Moreover, involving patients instead of healthy volunteers would invariably increase inter-subject variability and possibly intra-subject variability as well. ${ }^{3}$ 


\section{Messages}

Bioequivalence studies are performed on healthy volunteers. It is conventionally accepted that a similar bioavailability found in these people is a solid proof of a similar bioavailability in sick people too.

\section{Bioequivalence and types of drugs: not all the same?}

Bioequivalence criteria may be fine for most drugs, but some conditions may require drug levels with modified variations in the definition of an acceptable range for the area under the concentration (AUCt) and $\mathrm{C}_{\max }$ criteria.

\section{Narrow therapeutic index and critical-dose drugs}

The Food and Drug Administration (FDA) defines a drug as having a narrow therapeutic range if: i) there is less than a 2-fold difference between median lethal dose and median effective dose values; ii) there is less than a 2-fold difference between minimum toxic concentrations and minimum effective concentrations in the blood; iii) safe and effective use of the drug products require careful titration and patient monitoring. ${ }^{4}$

Table 1. Some clinical issues in the use of equivalent drugs.

Determination of bioequivalence by means of studies in healthy volunteers as a single dose

Bioequivalence and type of drugs: not all the same?

Narrow therapeutic index and critical-dose drugs

Highly variable drugs

Bioequivalence and type of patients: not all the same?

Elderly people, female patients, immunocompromised and transplant patients, patients with epilepsy

Therapeutic substitution and therapeutic interchange

When to switch and when not to switch?

Table 2. European Medicines Agency Guideline on the investigation of bioequivalence, CPMP/EWP/QWP/ 1401/98 Rev. 1/Corr**, London, 20 January 2010.

4.1.9 Narrow therapeutic index drugs

In specific cases of products with a narrow therapeutic index, the acceptance interval for AUC should be narrowed to $90.00-111.11 \%$. Where $\mathrm{C}_{\max }$ is of particular importance for safety, efficacy or drug level monitoring, the $90.00-111.11 \%$ acceptance interval should also be applied to this parameter. It is not possible to define a set of criteria to classify drugs as NTIDs and a decision must be made on a case-by-case basis, if an active substance is an NTID based on clinical considerations.

AUC, area under the concentration; NTIDs, narrow therapeutic index drugs.
The critical dose drugs are products for which comparatively small differences in dose or concentrations may lead to serious therapeutic failure and/or serious drug reactions. ${ }^{5}$ In specific cases of products with a narrow therapeutic index (NTI), dosing generally needs to be customized based on plasma concentration monitoring or titrated according to the clinical response, in order to avoid potential serious clinical consequences in the event of too low or high concentrations. In the case of products with a NTI, the acceptance interval may need to be narrowed and even further reduced to $90-111 \%$ to determine their bioequivalence (Table 2). ${ }^{6}$

There are lots of examples of patients taking drugs requiring careful titration and close tolerances - anticonvulsants, antifungals, thyroid replacement, and others - who had therapeutic failures when they switched to generics. The FDA does not formally publish a specific list of narrow therapeutic index or critical dose drugs. Some examples are reported in Table 3.

Generic substitution of NTI drugs has been a subject of interesting reviews. ${ }^{7-14}$

\section{Messages}

- Bioequivalence criteria may be fine for most drugs, but some conditions may require drug levels with modified variations in the definition of an acceptable range for the area under the concentration (AUCt) and $C_{\max }$ criteria.

- In the case of drugs with narrow therapeutic index, generic substitution should be avoided and strictly limited to well-defined medical indications.

\section{Highly variable drugs}

Highly variable drugs (HVDs) are defined as drugs whose rate and extent of absorption show large doseto-dose variability within the same patient for which within-subject variability in bioequivalence (BE) measures $\left(\mathrm{C}_{\max }\right.$ and/or AUC) are approximately $30 \%$ or higher. HVDs include many therapeutic classes with new and long-standing products. Some examples are: chlorpromazine, propafenone, verapamil, nadolol, simvastatin, atorvastatin, esomeprazole, pantoprazole, clarithromycin, paroxetine, risedronate, metaxalone, itraconazole, balsalazide, acitretin, verapamil, atovaquone, disulfiram, erythromycin, sulfasalazine, etc. ${ }^{15-17}$ The BE of HVDs formulations poses a problem in that their high variability requires a large numbers of subjects to achieve an adequate statistical power in BE studies. HVDs often fail to meet current regulatory acceptance criteria for average bioequivalence. ${ }^{18}$ One of the methods proposed to address the problems posed by these drugs foresees the possibility of extending arbitrarily the bioequivalence acceptance limits so as to 
have wider limits. For example, the $90 \%$ confidence interval around the geometric mean ratio of $\mathrm{C}_{\max }$ values might be required to fall within acceptance limits of $0.75-1.33$ or even $0.70-1.42^{19}$ (Tables 4 and 5). ${ }^{6,20}$

The scaled average bioequivalence is another method which is based on the use of within-subject variability: it may be useful to evaluate the BE of HVDs and meet the need for international guidelines for BE. ${ }^{18}$

\section{Bioequivalence and type of patients: not all the same?}

There are some patient subpopulations for whom generic substitution can still prove to be problematic. ${ }^{1}$ The use of generic drugs involves some problems in some special populations for whom relatively small plasma concentration of specific drugs - mostly with low therapeutic index - can have serious consequences, in terms of adverse effects or lack of efficacy. ${ }^{21}$ Generic drugs are not required to undergo bioequivalence testing in the elderly or children, unless they are the main target population of the drug. However, physiologic changes occur in young or old age individuals, including alterations in distribution volume, protein binding, elimination rates, and oral absorption from gastric $\mathrm{pH}$ and gastric emptying rates. ${ }^{22}$ Bioequivalence studies on generic drugs can control possible confounding factors, but do not reflect the real world, where drugs are taken by patients who are often elderly, with multimorbidity and concomitant polypharmacy, in situations that differ markedly from those reproduced in a highly controlled environment. ${ }^{1}$ However, this is a problem that affects all randomized clinical trials, even on originator drugs.

\section{Message}

There are some patient subpopulations for whom generic substitution can still prove to be problematic.

\section{Elderly people}

With increasing age, significant alterations occur in the pharmacokinetic/pharmacodynamic metabolisms of medications, predisposing elderly patients to adverse drug effects and drug-drug interactions: increased absorption of fat soluble drugs, decreased hepatic metabolism, reduced renal clearance, enhanced volume of distribution. Changes in pharmacokinetics and pharmacodynamics in elderly people obviously concern all drugs, i.e. both original and equivalent products. Many people, especially elderly patients, can be confused by color, appearance, packaging and labeling and find it difficult to identify their pill, thus becoming paradoxically less compliant in using generics, despite compliance should be at least equal or greater given the lower prices. Generic drugs are chemically equivalent to their brand-name counterparts in terms of active ingredients, but they may differ in their external features, such as pill color or shape, inner binders and fillers and in the manufacturing process. ${ }^{23}$ However the rules intended to check bioequivalence do not consider these pharmaceutical aspects. ${ }^{24}$ These factors can negatively influence compliance, mostly in elderly people who are already taking many drugs. Besides the distrust of doctors, especially those with several years of professional experience, the fear of patients in switching drugs branded pills with color and shapes, may have important consequences on their compliance. In order to limit confusion, it was proposed to the FDA to allow manufacturers of generic drugs to adopt the same trade dress (appearance) of the corresponding innovator drugs. ${ }^{25,26}$ Changes in pill color significantly increase the risk of nonpersistence in antiepileptic treatment, with potential important clinical implications, thus highlighting the need for reconsidering the current regulatory policy that admits significant differences in the ap-

Table 3. Narrow therapeutic index and critical dose drugs.

\begin{tabular}{ll}
\hline Therapeutic class & Some examples \\
\hline Antibiotics & Aminoglycosides \\
\hline Antifungals & 5-FU-flucytosine, ketoconazole, itraconazole, voriconazole, posaconazole \\
\hline Antiarrythmic drugs & Digoxin, disopyramide, flecainide, procainamide, quinidine \\
\hline Anticoagulant drugs & Warfarin \\
\hline Antiepileptic drugs & Carbamazepine, oxcarbazepine, phenytoin, valproic acid \\
\hline Antirejection drugs & Cyclosporine, everolimus, sirolimus, tacrolimus \\
\hline Bronchodilators & Theophylline \\
\hline Mood stabilizers & Lithium \\
\hline Syntetic hormones & Ethinyl estradiol, levothyroxine \\
\hline
\end{tabular}


pearance of bioequivalent drugs. ${ }^{27}$ In contrast with what is expected in chronic diseases, generic substitution of antihypertension drugs does not lead to lower compliance or more discontinuation and cardiovascular disease-related hospitalizations compared with the corresponding brand-name therapy. ${ }^{28}$

\section{Messages}

- Many people, especially elderly patients, can be confused by color, appearance, packaging, and labeling and find it difficult to identify their pill, thus becoming paradoxically less compliant in using generics, despite compliance should be at least equal or greater given the lower prices;

- A good communication between doctors and patients on the management of the disease can help compliance to the prescribed therapy.

\section{Female patients}

Except for drugs used entirely in one gender, bioequivalence studies are supposed to include a represen-

Table 4. European Medicines Agency Guideline on the investigation of bioequivalence, CPMP/EWP/QWP/ 1401/98 Rev. 1/Corr**, London, 20 January 2010.

\subsubsection{Highly variable drugs or drug products}

Highly variable drug products (HVDP) are drugs with an intra-subject variability for a parameter that is higher than $30 \%$. If an applicant suspects that a drug product can be considered highly variable in its rate and/or extent of absorption, a replicate crossover design study can be carried out.

Those HVDP for which a wider difference in $\mathrm{C}_{\max }$ is considered clinically irrelevant based on a sound clinical justification can be assessed with an extended acceptance range. In this case, the acceptance criteria for $\mathrm{C}_{\max }$ can be extended to a maximum of 69.84$143.19 \%,[\ldots]$. tative sample of men and women. Early drug studies did not include a representative proportion of women, despite the documented influence of sex on pharmacokinetics, ${ }^{29}$ but now women are being included in pharmacokinetic studies for new drug applications in accordance with the International Conference on Harmonization of Technical Requirements for Registration of Pharmaceuticals for Human Use (ICH), US FDA, and other guidelines (Table 6). ${ }^{31}$

\section{Immunocompromized and transplant patients}

There is a considerable debate on the efficacy and safety of generic drug substitution in solid organ recipients. In transplant patients, indiscriminate product switching without prescriber's consent is a major concern. ${ }^{32}$ The risk of switching may be manageable when patients receive their immunosuppression treatment in an hospital setting, but it becomes totally unmanageable in primary care, where there is less control over the brand prescribed to the patient. In 2011, the Advisory Committee of the Council of the European Society for Organ Transplantation issued its recommendations, which we summarized in Table $7 .^{33}$

Also the Italian Drug Agency (Agenzia Italiana del Farmaco, AIFA) addressed the topic of immunosuppressive equivalents after solid organ transplantation. A memorandum dated June 2011 on the use of a generic tacrolimus confirmed the need to avoid interchanges between original and equivalent drugs. It was established that: i) general practitioners (GP) have to stick to the trade name indicated in the treatment sheet of the patient, compiled by the medical specialist; ii) pharmacists have to dispense only the product prescribed by the GP; iii) patients must verify that the trade name of the drug matches the brand indicated on the treatment sheet; iv) it is recommended that local health authorities do not charge the patient for the dif-

Table 5. Acceptable limits for bioequivalence.

\begin{tabular}{ll}
\hline Parameters to be analyzed after a single dose & $\begin{array}{l}\text { AUCt } ; \mathrm{C}_{\max } \\
90 \% \text { i.c. T/R ratio } \geq 80.00 \leq 125.00\end{array}$ \\
\hline When the rate of absorption is important & $\begin{array}{l}\text { Also the partial } \mathrm{AUC} \\
\text { Same } 90 \% \text { i.c. } \mathrm{C}_{\max }\end{array}$ \\
\hline For SS studies & $\begin{array}{l}\mathrm{AUCt} ; \mathrm{C}_{\max }, \mathrm{SS} ; \mathrm{C}_{\min }, \mathrm{SS} \\
90 \% \text { i.c. T/R ratio } \geq 80.00 \leq 125.00\end{array}$ \\
\hline For products with narrow therapeutic margins & $\begin{array}{l}\text { AUCt and } \mathrm{C}_{\max } \\
\text { Decision based on the type of product } \\
90 \% \text { i.c. relations } \geq 90.00 \leq 111.00\end{array}$ \\
\hline For highly variable drugs & $\begin{array}{l}\text { AUCt and } \mathrm{C}_{\text {max }} \\
90 \% \text { i.c. relations } \geq 80.00 \leq 125.00 \text { per } \mathrm{AUCt}\end{array}$ \\
& $90 \%$ i.c. relations $\geq 75.00 \leq 133.00$ for $\mathrm{C}_{\text {max }}$ \\
& $(\mathrm{BE}$ with design replicated to show that the intra-subject variability is $>30 \%)$
\end{tabular}

AUC, area under the concentration; SS, steady-state; BE, bioequivalence. Adapted from Tajana, 2009. ${ }^{20}$ 
ference between the lower price and the expected price of the drug, as an exception to the provisions set out in the fourth paragraph of Art. 7 of Law 405/2001. In July 2011, in a subsequent note, it was recommended that: i) the switch from the original formulation to the generic or vice versa should always be closely monitored and managed by specialist physicians with experience in immunosuppressive therapy and in the management of transplant patients; ii) the use of equivalent drugs should be preferably made more in de novo patients than in those already receiving the branded drugs; iii) the responsability for switching formulations still belongs to the doctor; iv) the possibility by the prescriber to specify the non-substitutability of the product considered to be the most suitable is confirmed. Some safety principles have been reiterated by the Italian Society of organ transplantation: ${ }^{34}$ i) data from the literature confirms the possibility of using immunosuppressant equivalents, provided that the same drug equivalent is always used;

Table 6. Elderly people and female patients.

The Guidance for Industry, Bioavailability and Bioequivalence Studies for Orally Administered Drug Products - General Considerations recommends that: ${ }^{31}$

If the drug product is intended for use in both sexes, the sponsor must attempt to include similar proportions of males and females in the study;

If the drug product is to be used predominantly in the elderly, the sponsor should also attempt to include as many subjects of 60 years of age or older as possible. It is recommended that the total number of subjects in the study provides an adequate power for BE demonstration, but it is not expected that there will be sufficient power to draw conclusions for each subgroup.

$\mathrm{BE}$, bioequivalence. ii) during the observation period, the interchange between an originator drug and an equivalent or between equivalents should be avoided, because it may expose the patient to unexpected changes in the degree of immunosuppression; iii) when treatment is changed, the only way to ensure the patient safety is a careful clinical monitoring for a few months; iv) the monitoring program, which is expensive and challenging for every transplant center, can be implemented only if the change in the therapy occurs under the supervision of a specialist medical. Consequently, no change of therapy should be carried out without informing the referring physician. As far as savings are concerned, despite initial perceived positive results associated with generic ciclosporin A (CsA), de novo renal transplant recipients may face greater total healthcare costs than those treated with branded CsA, since higher doses or other immunosuppressants are needed to maintain the transplanted kidney as opposed to patients receiving branded CsA. ${ }^{35}$ Moreover, switching patients from one brand to another or one generic equivalent to another should be initiated only by the transplant physician and would require additional monitoring, clinic visits and dose titration. ${ }^{36}$

\section{Messages}

- In immunocompromized/transplant patients no change in therapy should be carried out without informing the referring physician.

- Switching may be manageable where patients receive the immunosuppression treatment in a hospital setting, but it may become unmanageable in primary care.

- Moreover, switching patients from one brand to another or one generic equivalent to another

Table 7. European Society for Organ Transplantation Advisory Committee guidelines for a safe and controlled generic substitution in solid organ recipients.

1. Switching between a brand name drug and a generic formulation, and also between different generic formulations should only be initiated by the transplant physician (in this report with this term we refer to a practitioner specialized in transplantation medicine, either a transplant physician or a transplant surgeon)

2. Each switch needs to be followed up closely to ensure that the correct therapeutic window is established

3. Repetitive consecutive substitutions to other generic formulations of the same drug should be avoided. To avoid repetitive substitutions between different generic formulations, it is recommended to prescribe a specific brand name generic formulation

4. Patients should be informed about generic substitution, they should be educated on how to identify the different formulations of the same drug, and they should alert the transplant physician if uncontrolled substitutions are made

5. New generic formulations of immunosuppressive drugs that do not fulfill stricter bioequivalence criteria should not be used. Similarly, the use of already marketed generic immunosuppressants should be discouraged, unless they prove to be bioequivalent according to the recently updated EMA guidelines

6. Further research is needed to fully explore the benefits and limitations of generic drug substitutions

7. In case of future substitution of biological to bio-similar immunosuppressive drugs, clinical bioequivalence criteria should be carefully formulated

EMA, European Medicines Agency, 
should be initiated only by the transplant physician and would require additional monitoring, clinic visits and dose titration.

\section{Patients with epilepsy}

A complex discussion continues over generic substitution of antiepileptic drugs (AEDs). Newer AEDs may be less prone to problems with generic substitution than older ones, but unfortunately, very few data are available to guide decisions regarding what is best for an individual patient. ${ }^{2}$ In a systematic review and meta-analysis of randomized controlled trials and observational studies, conflicting data emerged, suggesting the need for a more intensive monitoring of high-risk patients taking AEDs, when any switch occurs. $^{37}$ When switching to generic formulations, healthcare providers and people with epilepsy would do well to proceed cautiously and understand the potential risks and benefits of substitution. Extra caution may be needed for patients at highest risk of seizure complications, such as pregnant patient, patients with recurrent status epilepticus, or patients who have been seizure-free for long periods of time and are driving. ${ }^{38}$ The American Epilepsy Society's position is that formulation substitution should not take place without the physician and patient approval. ${ }^{39}$ In Italy, recommendations of the Italian League Against Epilepsy (LICE) study group are based schematically on the following points: i) in patients who achieved complete clinical remission, it is not recommended to replace the drug in use; ii) in patients in treatment with a generic product, it is preferable to avoid substitution of the same with a different generic; iii) in patients already treated with a brand product, but with incomplete control on seizures, it may be acceptable to replace the product with a generic, after discussing with the patient, provided plasma drug levels are adequately monitored; iv) in naïve patients starting treatment (initial monotherapy or additional prescription) with generic drugs may be, after informing the patients, a good choice, which can sometimes offer benefits in terms of costs; v) AEDs modified-release formulations are not interchangeable with immediaterelease drugs. ${ }^{40}$

In conclusion, a large bulk of data suggests that antiepileptic drug generic substitution is associated with more health problems, but no sufficient detailed information on seizure control and blood levels is provided. Several ongoing prospective randomized trials will provide additional data for better decision-making. ${ }^{41}$

\section{Messages}

- In epileptic patients, specific recommendations suggest not to change drugs when complete remis- sion is achieved. In these patients it is not recommended to replace the drug taken;

- In patients in treatment with a generic product, it is preferable to avoid substitution with a different generic;

- In patients already treated with a brand product, but with incomplete control on seizures, it may be acceptable to replace the product with a generic, after discussing with the patient, provided plasma drug levels are adequately monitored.

In naïve patients starting treatment (initial monotherapy or additional prescription), it may be a good to choice to prescribe generic drugs, after duly informing the patients.

\section{Therapeutic substitution and therapeutic interchange}

According to the 2011 ACCF/AHA Health Policy Statement on Therapeutic Interchange and Substitution, therapeutic substitution is markedly different than therapeutic interchange. Therapeutic substitution is therapeutic interchange without prior authorization from the initial prescriber. The use of therapeutic substitution is rare; however, this strategy should never be accepted, unless reviewed and approved by the healthcare team based on the scientific data available. ${ }^{5}$

\section{When to switch and when not to switch?}

Not all generic drugs are as effective as their brandname counterparts. Switching inequivalent products may lead to lower or higher blood concentrations of a drug in patients. This may increase the risk of therapeutic failure or drug-related toxicity. For most drugs, current bioequivalence testing generally enables clinicians to routinely substitute innovator products with generics. When starting a new therapy with any generic drug, however, its similarity to the innovator drug in terms of efficacy, safety and quality is guaranteed. Some particular drugs may not be ideally suited for generic substitution, when a patient is already taking them. These are the so-called critical dose medicinal products (drugs with a narrow therapeutic range) ${ }^{42}$ There are several clinical areas or drug types for which brand prescribing may be considered preferable, because of potential therapeutic inequivalence or confusion (Table 8). ${ }^{43}$

\section{Conclusions}

Generic drugs are still underused in Italy, and more research is needed in this field. ${ }^{44}$ These drugs typically cost $30 \%$ to $60 \%$ less than their brand-name counterpart, ${ }^{45}$ mostly when compared with the drugs still covered by patents. The use of drugs with an expired patent is essential for the sustainability of the public national healthcare system in Italy (Table 9). ${ }^{46}$ 
Physicians often prescribe a brand-name drug to a patient, despite a corresponding generic is available, because the patient actually asks for it. The generic hurdle is common to many drug classes, such as statins, proton pump inhibitors, antidepressants and angiotension II receptor blockers, etc. ${ }^{47}$ This practice, which is not always unrelated to the influence of the pharmaceutical industry, can lead to unnecessary costs and a substantial increase in the expenditure of the healthcare system. ${ }^{48}$ Widespread use of generics has the potential to reduce the price of other brand-name drugs by creating more competition. ${ }^{49}$ A strategy aimed to increase a systematic spread of generics is to prescribe generic drugs at any hospital discharge. ${ }^{50}$ There are some basic facts in favor of generics: i) they have already been used for a long time, therefore they are substantially well known in terms of quality, efficacy and safety; ii) the price reduction defined by law in at least 20\% (although currently the price reduction can reach over $60 \%$ of the retail price) allows to allocate resources to innovative medicines without giving up long-established treatments; iii) they offer an opportunity for saving money not only to the National Health Service, but also to citizens. Promoting generic prescribing among specialists and generalists may increase opportunities for patients and payers to reduce spending on prescription drugs. ${ }^{51}$ The decision to substitute a prescribed medication with an alternative product must occur within the framework of a clinical decision-making process that must be based on appropriate medical evidence, therapeutic equivalence information, financial factors, and considerations on how the substitution will impact the patient. ${ }^{52}$ As to the decision on the actual substitutability or unsubstitutability of drugs, the doctors have this exclusive responsibility, that cannot be delegated to others. They are the ones who are supposed to decide upon the interchangeability of an originator with a generic, a generic with a branded drug and also between two equivalent medicines. The physician's decision not to endorse interchangeability must be based on his relationship with the patient and his knowledge of his/her clinical picture and take into account any implication in terms of therapeutic efficacy for the subject, specific contraindications, and also specific difficulties for the patients or the caregivers to comply with treatment. ${ }^{53}$ Before prescribing a new drug, above all in case of an unfamiliar drug names, doctors should check what they are prescribing and what are the other medications the patient is taking. Also patients should have a good familiarity with their medicines. In any case, it is necessary for an open communication to be established among those who prescribe, supply, and administer medicines, and those who actually take them. ${ }^{54}$ Before substituting a generic product, physicians and other decision-makers should consider potential clinical and pharmacoeconomic consequences: overtreatment, undertreatment, adverse effects, additional expenses, cost savings. ${ }^{55} \mathrm{~Pa}-$

Table 8. Medicines for which prescribing branded versions might be safer, more effective, or reduce the risk of medication error.

\begin{tabular}{|c|c|}
\hline Problem & Some examples \\
\hline $\begin{array}{l}\text { Where there is a difference in bioavailability between brands of the same } \\
\text { medicine, particularly if the medicine has a low therapeutic index }\end{array}$ & $\begin{array}{l}\text { Ciclosporin, lithium, CFC-free beclometasone metered dose } \\
\text { inhalers, carbamazepine }\end{array}$ \\
\hline Where modified release preparations are not interchangeable & $\begin{array}{l}\text { Prolonged release preparations of carbamazepine, theophylline, } \\
\text { diltiazem, aminophylline, mesalazine, nifedipine, morphine and } \\
\text { oxycodone }\end{array}$ \\
\hline Where pharmacokinetic differences may be evident & Phenytoin \\
\hline $\begin{array}{l}\text { Where there are important differences in formulation between brands of } \\
\text { the same medicine }\end{array}$ & $\begin{array}{l}\text { Adrenaline pre-filled syringes, transdermal formulations of } \\
\text { fentanyl, buprenorphine }\end{array}$ \\
\hline $\begin{array}{l}\text { Where products contain multiple ingredients and brand name prescribing } \\
\text { AIDS identification }\end{array}$ & $\begin{array}{l}\text { Combination topical preparations, hormone replacement } \\
\text { therapy, oral contraceptives, pancreatin supplements, antacids } \\
\text { preparations containing simeticone }\end{array}$ \\
\hline Where there is a significant danger of medication error & Tacrolimus \\
\hline $\begin{array}{l}\text { Where administration devices (e.g. inhaler or self-injection) have different } \\
\text { instructions for use and patient familiarity with the same product is important }\end{array}$ & $\begin{array}{l}\text { Dry powder inhaler devices, insulin, apomorphine, estradiol } \\
\text { transdermal patches, somatropin injection cartridges, } \\
\text { alprostadil injection, interferons }\end{array}$ \\
\hline $\begin{array}{l}\text { Where different preparations of the same medicine have different licensed } \\
\text { indications }\end{array}$ & Cyproterone, sildenafil, duloxetine, bisoprolol, buprenorphine \\
\hline Where the product is a biological rather than a chemical entity & Biosimilars, vaccine products \\
\hline
\end{tabular}

CFC, chlorofluorocarbon compounds. 
tients on chronic treatment receiving generic products, which may be frequently changed in the course of treatment, according to availability or cost, may be at risk of anomalies or discontinuities in their treatment. The American Medical Association strongly recommends that therapeutic interchange in patients with chronic diseases who are stabilized on a drug therapy regimen be discouraged. ${ }^{5}$ A reasonable rule could be that in stabilized chronic patients you should not change treatment, especially when drugs with narrow therapeutic index or some special formulations, such as powders or aerosol dispensers extended release, are prescribed. ${ }^{56}$ In frail populations and in the case of low therapeutic index drugs, there are reasons not to fulfill necessarily the obligation (or the habit) of replacing a product with another, even if bioequivalent. ${ }^{57}$ Further problems are the management of drugs with long halflives and those with an intrinsically highly variable clearance. ${ }^{58}$ The replacement of a brand product with an equivalent must occur under the control of the physician in charge. At some point in their interaction with individual patients, physicians should inform them that generics are available as substitutes for some more expensive brand-name medications, and that they are equivalent in terms of efficacy and safety. The collaboration among physicians, pharmacists, and patients can enable them to optimize treatment, while cutting costs. ${ }^{59}$ Moreover, we would need a specific list of narrow therapeutic index or critical dose drugs.

Finally, we hope that also in Italy a tool similar to the American Orange Book will soon be made available by the regulatory Authorities. In fact, besides providing specific transparency lists, not only can it ensure a better control of the drug pricing system and the implementation of good manufacturing practices, but it can also offer a meticulous assessment of bioequivalence. This can be beneficial to both physicians, who can enhance their ability to prescribe the most appropriate drugs, and to patients, who can be better informed.

\section{Use of equivalent drugs in internal and general medicine patients: 10 learning points}

i) Despite compelling evidence and guidelines, in Italy generic drugs are still underused; generic drugs are equivalent to their brand-name counterparts in terms of active ingredients; generic drugs typically cost $30 \%$ to $60 \%$ less than those still covered by patents;

ii) In order to enhance the sustainability of the healthcare system, all doctors should facilitate as far as possible an extensive use of generic drugs; any clinical scenario that would require choosing something other than the lowest-priced option, generally means choosing generic drugs; in any new treatment, equivalent drugs use has to be implemented as much as possible, according to the characteristics of the patient, the disease and the used active principles; a strategy aimed to increase a systematic spread of generics could be based on the prescription of generic drugs at the time of the discharge from hospital;

iii) In naïve patients starting treatment (initial monotherapy or additional prescription) generic drugs may be, after duly informing them, a good, if not the best, choice, that can sometimes offer significant benefits in terms of costs; it may be advisable to prescribe generics whenever the outcome to be achieved is clinically easy to measure, i.e. drugs for pain control, blood pressure, and so forth;

iv) Therapeutic substitution in patients with stabilized chronic diseases on a branded drug therapy should be discouraged without the permission of the first prescriber and/or the attending physician;

v) Generics may differ in external features, such as pill color or shape, inner binders and fillers and manufacturing processes. The rules intended to check bioequivalence do not consider these pharmaceutical aspects. However these factors can negatively influence compliance to therapy,

Table 9. Drugs with expired patent and generic drugs.

- The use and prescription of drugs with expired patents plays a fundamental social role, which is important for the sustainability of our national public health service

- The use of a first-choice drug with an expired patent (be it branded or unbranded) can ensure treatment efficacy and safety as well as an appropriate use of resources

- Given the current regulatory framework, the prescription of drugs with expired patents (be them branded or unbranded) allows us to ensure treatment continuity

- In a context of a good patient/doctor communication, the prescription of equivalent drugs can preserve their freedom of choice - in their respective roles as patients and physicians

Adapted from Gruppo di lavoro CF AVEC Emilia Romagna, 2013. ${ }^{46}$ 
mostly in the elderly patient already taking many drugs; especially in frail populations there are reasons not to fulfill the obligation of replacing a product with another, even if bioequivalent; a better communication between doctors and their (mostly old and very old) patients can help improve their compliance to the prescribed therapy;

vi) Some particular drugs (such as critical dose medicinal products/drugs with a narrow therapeutic range) may not be ideally suited for generic substitution, when a patient is already on brand drugs; the drugs that have a narrow therapeutic index pose the most significant problems of substitutability, because small changes in bioavailability, when switching from branded to generic products may give rise to seizable variations in efficacy and/or tolerability. These classes include some antibiotics, antifungals, antiarrythmics, anticoagulants, anticonvulsants, antirejection drugs, theophylline, mood stabilizers, synthetic hormones. Generic substitution for drugs with narrow therapeutic index should be avoided and limited exclusively to strict medical indications. In particular, in the case of these drugs, any shift from the original formulation to the generic or viceversa should always be prescribed by the attending physician and/or the specialist in charge and and be managed under their close clinical monitoring. Transplant patients should be informed about generic substitution, they should be educated about how to identify the different formulations of the same drug, and they should be instructed to alert their transplant physician, if uncontrolled substitutions occur. Each switch/ substitution needs to be followed closely to ensure that the correct therapeutic window is established. In patients already in treatment with a generic product, it is preferable to avoid substitution of the same with a generic of a different equivalent type;

vii) The interchangeability between brand/equivalent drugs should also be based on the interaction between the patient and his caregivers, who must be aware of their specific clinical pictures both in relation to the verified therapeutic efficacy of the drugs and to any specific contraindications and known difficulties in terms of compliance to treatment;

viii) Before prescribing a new drug, all the more so in the case of an unfamiliar name on a prescription, prescribers should check what they are prescribing and the other medications the patient is taking;

ix) Patients should be familiar with their medicines. At all times a good communication among those who prescribe, supply, and administer medicines, and those who take them is highly advisable. At hospital admission, at discharge and at each control/outpatient visit, physicians have to reconcile drugs to ensure the best compliance to treatment, introducing, whenever possible, equivalent medications;

x) Any doctor has be aware of medicines for which prescribing by brand and/or equivalent drug might be more cost-effective, but always safer, more effective and/or less risky in terms of medication errors. Clinicians should always be very careful in reporting any adverse unwanted event, that can be potentially related both to the use of generic and original drugs.

\section{References}

1. Meredith P. Bioequivalence and other unresolved issues in generic drug substitution. Clin Ther 2003;25:2875-90.

2. Shaw SL, Hartman AL. The controversy over generic antiepileptic drugs. J Pediatr Pharmacol Ther 2010;15: 81-93.

3. Fukuntoto KH. Generic drug substitution: role and function, legislative reform. Hawaii 16813, report no. 7. Honolulu: Bureau State Capitol; 1990.

4. US Food and Drug Administration. Code of Federal Regulations. Title 21 - Part 320: Bioavailability and bioequivalence requirements. Section 320.24. Types of evidence to measure bioavailability or establish bioequivalence. Silver Spring, MD: FDA; 2003. Available from: http:// www.accessdata.fda.gov/scripts/cdrh/cfdocs/cfcfr/cfrsear ch.cfm?fr $=320.24$

5. Holmes DR Jr, Becker JA, Granger CB, et al. ACCF/ AHA 2011 health policy statement on therapeutic interchange and substitution: a report of the American College of Cardiology Foundation Clinical Quality Committee. Circulation 2011;124:1290-310.

6. European Medicines Agency-Committee For Medicinal Products For Human Use (EMA-CHMP). Pre-authorisation evaluation of medicines for human use - Guideline on the investigation of bioequivalence. Doc. Ref.: CPMP/EWP/QWP/1401/98 Rev. 1. 24 July. London: EMA; 2008. Available from: http://www.ema.europa.eu/ docs/en_GB/document_library/Scientific_guideline/200 9/09/WC500003011.pdf

7. Pope ND. Generic substitution of narrow therapeutic index drugs. Generic Drug Rev 2009;34:12-9.

8. Reiffel JA. Issues in the use of generic antiarrhythmic drugs. Curr Opin Cardiol 2001;16:23-9.

9. Bolton S. Bioequivalence studies for levothyroxine. AAPS J 2005; 7:E47-53.

10. Crawford P, Feely M, Guberman A, Kramer G. Are there potential problems with generic substitution of antiepileptic drugs? a review of issues. Seizure 2006;15: 165-76.

11. Gidal BE, Tomson T. Debate: substitution of generic drugs in epilepsy: is there cause for concern? Epilepsia 2008;49:56-62.

12. Hope KA, Havrda DE. Subtherapeutic INR values associated with a switch to generic warfarin. Ann Pharmacother 2001;35:183-7. 
13. Milligan PE, Banet GA, Waterman AD, Gatchel SK. Substitution of generic warfarin for Coumadin in an HMO setting. Ann Pharmacother 2002;36:764-8.

14. Vasquez EM, Min DI. Transplant pharmacists' opinions on generic product selection of critical-dose drugs. Am J Health Syst Pharm 1999;56:2246-7.

15. Blume H, Zhong D, Elze M. Advantages of a steadystate crossover design in assessment of bioequivalence of highly variable drugs: propafenone. Eur J Pharm Sci 1994;2:385-93

16. Health Canada, Therapeutic Products Directorate (TPD). Discussion paper on "Bioequivalence requirements - highly variable drugs and highly variable drug products: issues and options". Expert Advisory Committee on Bioavailability and Bioequivalence (EAC-BB) Meeting, June 26-27, 2003.

17. Diliberti CE. Why bioequivalence of highly variable drugs is an issue. In: FDAAdvisory Committee for Pharmaceutical Sciences and Clinical Pharmacology meeting transcript. US Food and Drug Administration Dockets; Apr 14 2004. Available from: http://www.fda.gov/ ohrms/dockets/ac/04/transcripts/4034T2.htm

18. Tothfalusi L, Endrenyi L, Arieta AG. Evaluation of bioequivalence for highly variable drugs with scaled average bioequivalence. Clin Pharmacokinet 2009;48:725-43.

19. Midha KK, Rawson MJ, Hubbard JW. The bioequivalence of highly variable drugs and drug products. Int $\mathrm{J}$ Clin Pharmacol Ther 2005;43:485-98.

20. Tajana A. Bioequivalenza: la nuova linea guida dell'EMEA, $49^{\circ}$ Simposio AFI - Giugno 2009. Available from: http://www.afiscientifica.it/all/TAJANA.pdf

21. Perucca E. Equivalenti nelle sotto-popolazioni fragili: il punto di vista del farmacologo. BIF 2008;3:118-20.

22. Gidal BE. Antiepileptic drug formulation and treatment in the elderly: biopharmaceutical considerations. Int Rev Neurobiol 2007;81:299-311.

23. Peters JR, Hixon DR, Conner DP, et al. Generic drugs safe, effective and affordable. Dermatol Ther 2009;22: 229-40.

24. Marzo A, Porro E, Barassi A. Generic drugs: myths, facts, and limitations. Ital J Med 2012;6:146-52.

25. Greene JA, Kessleheim AS. Why do the same drugs look different? Pills, trade dress, and public health. N Engl J Med 2011;365:83-9.

26. Emery J, McKenzie A, Bulsara C, Holman D. Controversy over generic substitution. BMJ 2010;341:c3570.

27. Kesselheim AS, Misono AS, Shrank WH, et al. Variations in pill appearance of antiepileptic drugs and the risk of nonadherence. JAMA Intern Med 2013;173:202-8.

28. Van Wijk BL, Klungel OH, Heerdink ER, de Boer A. Generic substitution of antihypertensive drugs: does it affect adherence? Ann Pharmacother 2006;40:15-20

29. Schwartz JB. The influence of sex on pharmacokinetics. Clin Pharmacokinet 2003;42:107-21.

30. McGilveray IJ. Bioequivalence studies of drugs prescribed mainly for women. Popul Ther Clin Pharmacol 2011;18:e516-22.

31. US Food and Drug Administration. Guidance for industry. Bioavailability and bioequivalence studies for orally administered drug products - General considerations. Revision 1, March 2003. Available from: http://www. fda.gov/downloads/Drugs/.../Guidances/ucm070124.pdf

32. Harrison J. Safety considerations associated with generic interchangeability in transplant medicine. Toronto General Hospital, University Health Network; 21 Sept 2011. Available from: http://www.benefitscanada.com/wp-content/uploads/2011/09/JenniferHarrison-Astellas.pdf

33. European Society for Organ Transplantation. Advisory Committee on generic substitution of immunosuppressive drugs; March, 2011.

34. Società Italiana Trapianti d'Organo. Considerazioni sull'uso degli immunosoppressori equivalenti dopo trapianto d'organo solido; II stesura, 2011. Available from: http://www.societaitalianatrapiantidiorgano.com/ documenti/Farmaci_generici_SITO.pdf

35. Helderman JH, Kang N, Legorreta AP, Chen JY. Healthcare costs in renal transplant recipients using branded versus generic ciclosporin. Appl Health Econ Health Policy 2010;8:61-8.

36. van Gelder T; ESOT Advisory Committee on Generic Substitution. European Society for Organ Transplantation Advisory Committee recommendations on generic substitution of immunosuppressive drugs. Transpl Int 2011;24:1135-41.

37. Kesselheim AS, Stedman MR, Bubrick EJ, et al. Seizure outcomes following use of generic vs. brand-name antiepileptic drugs: a systematic review and meta-analysis. Drugs 2010;70:605-21.

38. Privitera MD. Generic antiepileptic drugs: current controversies and future directions. Epilepsy Curr 2008;8: 113-7.

39. American Epileptic Society. Position statement on the substitution of different formulations of antiepileptic drugs for the treatment of epilepsy; November 29, 2007. Available from: http://www.aesnet.org/go/press-room/ consensus-statements/drug-substitution

40. Perucca E, Albani F, Capovilla G, et al. Raccomandazioni del gruppo di studio LICE in merito all'utilizzo di prodotti generici di farmaci antiepilettici. Boll Lega Ital Epil 2007;135:33-9.

41. Privitera M. Generic substitution of antiepileptic drugs: What's a clinician to do? Neurol Clin Pract 2013;3: 161-4.

42. Tschabitscher D, Platzer P, Baumgärtel C, Müllner M. Generic drugs: quality, efficacy, safety and interchangeability. Wien Klin Wochenschr 2008;120:63-9.

43. Duerden MG, Hughes DA. Generic and therapeutic substitutions in the UK: are they a good thing? Br J Clin Pharmacol 2010;70:335-41.

44. Garattini S. Maggiore ricerca per i farmaci generici. Ital J Med 2012;6:145.

45. Zarowitz BJ. The generic imperative. Geriatr Nurs 2008;29:223-6.

46. Gruppo di lavoro CF AVEC (Commissione Farmaco Area Vasta Emilia Romagna Centro). I farmaci a brevetto scaduto. Bologna: Servizio Sanitario Regionale Emilia-Romagna; 2013. Available from: http://www. odmbologna.it/ViewPost/Index/2231

47. Green JB, Ross JS, Jackevicius CA, et al. When choosing statin therapy: the case for generics. JAMA Intern Med 2013;173:229-32.

48. Campbell EG, Pham-Kanter G, Vogeli C, Iezzoni LI. Physician acquiescence to patient demands for brandname drugs: results of a national survey of physicians. JAMA Intern Med 2013;173:237-9. 
49. Lewek P, Kardas P. Generic drugs: the benefits and risks of making the switch. Family Practice 2010;59:634-40.

50. Chu C, Rudant E, Bonvalet M, et al. Generic drug prescriptions following hospital discharge: a prospective study in France. J Intern Med 2011;22:e45-9.

51. Federman AD, Halm EA, Siu AL. Use of generic cardiovascular medications by elderly medicare beneficiaries receiving generalist or cardiologist care. Medical Care 2007;45:109-15.

52. Manolakis PG. Prescription drug pro duct substitution decision support. J Am Pharm Assoc 2007;47:328-38.

53. Milillo G. Il punto di vista di FIMMG. Giorn Ital Farmacoecon Farmacoutil 2013;1:46.

54. Aronson JK. Medication errors resulting from the confusion of drug names. Expert Opin Drug Saf 2004;3: 167-72.
55. Sabatini S, Ferguson RM, Helderman JH, et al. Drug substitution in transplantation: a National Kidney Foundation White Paper. Am J Kidney Dis 1999;33:389-97.

56. Redazione di Dialogo sui Farmaci (a cura di). Farmaci generici: dubbi o pregiudizi? un sondaggio di Dialogo sui Farmaci. Dialogo sui Farmaci 2007;2:75-7. Available from: http://www.dialogosuifarmaci.it/rivista/pdf/ CO-200703-2_1089.pdf

57. Perucca E. Equivalenti nelle sotto-popolazioni fragili: il punto di vista del farmacologo. BIF 2008;3:118-20.

58. Marzo A, Porro E, Barassi A. Generic drugs: myths, facts, and limitations. Ital J Med 2012;6:146-52.

59. Caldwell DJ, Jaubert K, Zagar M, Sherman J. Considerations for generic drug use in the elderly. Pharmacy Times 2007, Jan 1. Available from: http://www.pharmacytimes. com/publications/issue/2007/2007-01/2007-01-6215 